\title{
Changes of Clothing Distribution Logistics Management-RFID Technology
}

\author{
Yuzhen Sun ${ }^{1}$, Xufen Huang ${ }^{1}$, Ting Zhang ${ }^{1}$, Jun Pi $^{2}$ \\ ${ }^{1}$ College of Fashion, Shanghai University of Engineering Science, Shanghai, China \\ ${ }^{2}$ College of Economy and Management, Aurora College, Shanghai, China
}

Email address:

pijun2003@163.com (Jun Pi)

\section{To cite this article:}

Yuzhen Sun, Xufen Huang, Ting Zhang, Jun Pi. Changes of Clothing Distribution Logistics Management—RFID Technology. Science Journal of Business and Management. Vol. 4, No. 3, 2016, pp. 72-76. doi: 10.11648/j.sjbm.20160403.12

Received: March 24, 2016; Accepted: April 9, 2016; Published: May 14, 2016

\begin{abstract}
Firstly, the paper analyzed the necessity and practical application advantages of the RFID technology in the clothing distribution logistics management, and pointed out the urgency and future trends in the domestic logistics applications of apparel industry. Then, it proposed the overall architecture of clothing distribution logistics management system, So as to help enterprises introduce RFID technology and realize the enterprise logistics and information flow automation, real-time, visualization, accuracy and real-time tracking management, so that clothing enterprises can quickly response to the implementation of garment enterprises lean management. The framework of logistics management system was constructed in this research, which hoped to be able to solve the problem of logistics bottleneck in the sustainable development of garment enterprises.
\end{abstract}

Keywords: Clothing Distribution Logistics, RFID Technology, Visualization, Lean Management

\section{Introduction}

With the high-speed development of modern enterprises, the issues of clothing logistics which is not paid enough attention in the past become increasingly prominent. It has become a bottleneck restricting the development of enterprises. And RFID technology is the core of the modern IOT (Internet of things), and it has been widely used and achieved good results in the field of supply chain management, logistics management etc. And now the RFID technology is gradually applied to the clothing industry production, warehousing, distribution logistics and sales. The paper designed a architecture of the logistics system for garment enterprises based on RFID technology through extensive literature reading and the professional knowledge reserves, which may bring new enlightenment and suggestions for the garment enterprises logistics modernization reform.

\section{An Overview of Clothing Distribution Logistics Management System}

Clothing distribution logistics management system is a kind of enterprise information management system that utilizes the logistics software and information network for determining strategy and scheme. Logistics information technology is a method and tool to collect, analyze and manage the logistics information resources. Through the comparative analysis of the traditional distribution logistics and modern distribution logistics management characteristics, it is necessary to introduce advanced information technology to realize information and digitization of clothing distribution logistics.

\section{Comparative Analysis of a RFID-Based Clothing Distribution Logistics and Traditional Logistics}

\subsection{The Situation of Traditional Logistics Management System}

Many links of traditional clothing distribution logical communication are done by manual work. And a lot of information dispersed on each node of enterprise interior. So it caused member clothing enterprises lacked sharing and 
exchange platform of supply and demand information, leading logistics information can not be real-time accessed and widely exchanged. Currently, many domestic clothing distribution logistics management system is using bar code technology, which is a very widely used automatic identification technology, yet a visual recognition technology. However, there are many shortcomings with the bar code technology. For example, it can not make information opaque and shared in real time, which caused companies were not able to respond quickly to customers' needs and post control of goods, so that the bar code technology can not meet the development requirements of modern enterprises. While the emerging of the RFID technology is gradually changing and improving the information and digitization of the clothing distribution logistics management system.

\subsection{The Advantage and Necessity of RFID in the Clothing Distribution Logistics Management Applications}

\subsubsection{The Advantage of RFID in the Clothing Distribution Logistics Management Applications}

According to the characteristics of clothing products management itself, the advantage is that achieves visualization and traceability of the clothing distribution logistics management through the use of RFID technology established clothing distribution logistics management system. And operations center can timely obtain information of every manufacturer and sales outlets to improve management efficiency. The interpretation will be made two aspects as follows:

(1) The management manufacture and products

Using RFID reader worked out a unique code for every apparel products from the production sides, such as type, style, fabric, color, etc. And if warehouse staffs want to check and obtain information that product was warehousing or out of storage, they only need to scan box scale to be completed easily, as well warehouse staffs made an inventory and other warehouse products work. This saved time to rummage clothing and cargo turnaround, but also improved the accuracy and trace ability of clothing distribution logistics management.

(2) Retail management

1) Reducing difficulty of inventory and display management. Staffs of retail merchandise can obtain the number, styles and total amount of money of the clothing storage directly by scanning RFID tags. And they no longer need to carry out inventory count daily, as well to know accurate inventory position of each style, size, etc. But they can also get suitable size for their customers fast in the sales process. In addition, using tracking and intelligent display of the RFID technology's function, each item can be obtained in real-time sales status and location at any time. So managers or salespersons can also display shelves of clothing in a timely manner to correct the position and supply commodities, even when it is peak flow of people in the store. As a result it largely reduced the store management difficulty and coefficient workload for staffs in retail.

2) Improving experience of customer shopping. Customers can experience virtual fitting and smart payment function modules by RFID tags to enhance the shopping experience. When the flow of people is high traffic, the customer does not need to queue to pay. And it is no longer the factor that leads the store to reduce the volume. For example, customers do not want to personally dressing since trouble dressing or weather problems, or they can not find a suitable outfit and so on. Because the RFID technology will improve customer shopping experience greatly.

3) Fully exploiting customer information. Some valuable hidden data, such as: store traffic, customer number and pick up clothing fitting times etc. and they can be accurately captured by RFID technology on sales terminals, which can offer decision support for the next season's fashion design and procurement. Furthermore, when operation center get available information about all aspects of logistics by the clothing distribution logistics management system effectively, they can real-time monitor the whereabouts of every clothes, and make development of marketing strategies timely based on the results of the analysis about information obtained. Besides its electronic information instead of the paper, greatly improving the management efficiently, and the RFID technology bring about management automation and visualization.

\subsubsection{The Necessity of RFID in the Clothing Distribution Logistics Management Applications}

Due to the characteristics of the clothing distribution logistics, logistics information and directions of the actual activity is changing with space and time. However, we must make the logistics information transparency and visualization, in order to facilitate business management, and enhance the reaction rate and improve profitability of clothing enterprises. Fortunately, the application of the RFID technology can help enterprises complete a variety of business operations efficiently. Since the RFID tags can move with different entities in different aspects of the clothing distribution logistics. It can input and output data to different systems in different areas, which maximizes the sharing of resources in different parts of the clothing logistics, as well real-time accesses logistics and product information. So that its frequency was increased in internal and external logistics information exchanging, achieving the clothing distribution logistics management information largely.

\subsection{The Principle of the RFID Technology Application in the Field of Logistics}

RFID (Radio Frequency Identification), Chinese called it radio frequency identification technology, which is a non-contact automatic identification technology. This technology can identify a specific target and write related data by radio signals, which have the characteristics of automatic identification, without human intervention, no mechanical or 
optical contact. And RFID (radio frequency identification technology) consists of electronic tags, readers, antennas, computer system. As follows state:

1) The electronic tags: The electronic tags include RFID chip and the antenna that attached to the object to identify the target object, and each tag has a unique electronic code, which stored information about object to be identified.

2) The reader: the reader is a device that used radio frequency technology to read and write information of the electronic tag. When the RFID system was working, it generally issued a special radio frequency signal by the reader, and the response signal that carried the electronic tag data information was given by the electronic tag. Then the reader received the response signal of its processing and conducted it, after that it transmitted to the host.

3) The antenna: The antenna is an intermediary substance between the reader and the electronic tag, which was used to collect electromagnetic waves that were transmitted to the space by the reader. And then the data signal of the label itself was launched out in the form of electromagnetic waves.

4) The computer system: The reader was connected with the computer network by a way of the standard interface. Finally computer network accomplished these activities, such as data processing, information transportation and communications. The RFID systems have a basic work process. It can make a two-way and non-contact transmission for data between the electronic tag and reader through the use of radio frequency mode, in order to achieve the purposes of target recognition, data transmission and conformity.

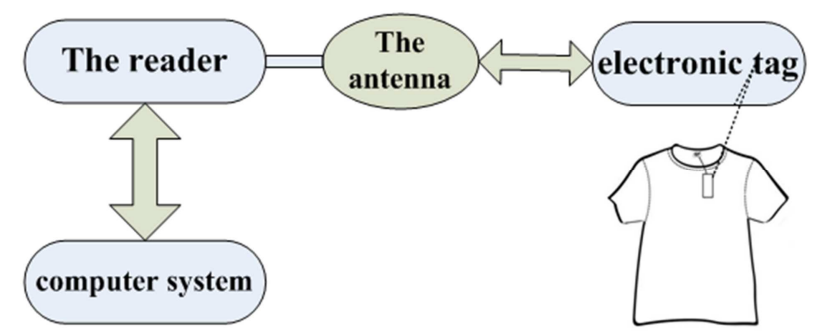

Figure 1. The working principle of the RFID technology.

After the electronic tags into the magnetic field, if they received a special RF signal that was issued by a reader, it can send out product information stored in the chip by an energy that can be obtained by induced current. Besides, the antenna is generally integrated among the electronic tags and readers as an electronic communication medium between the tag and reader. Moreover the reader can read and identify product data that stored in electronic tag without contact by an antenna. And the reader is also able to decode the information collected. As well the information will eventually be sent to the back-end business management system, and simultaneously the system conducts related operations for the stored data in order to get useful information, and working principle shown in Figure 1.

The main principle of the process is:

1) The reader sends out signal through an antenna.

2) The electronic tag was received signal, and was activated, and then it sent out the correct information.

3) The reader brings information and data into the computer system for data collection, processing and registration.

\section{Application Design of the RFID in Clothing Distribution Logistics Management System}

\subsection{The Architecture and Principle of the System}

This thesis was about how to build a more complete system, which set product production logistics, distribution logistics, retailed logistics as one of the clothing distribution logistics management system. And the system was based on the traditional clothing distribution to introduce an advanced RFID acquisition technology. That is to say that combines the RFID technology, the network technology, the computer technology, the database technology and the mobile communications technology, so that can make all links of the clothing distribution logistics achieve transparent information and visualization, in order to track and monitor the entire journey.

Overall objective:

1) Complete the RFID technology foundation application design in product information, in order to achieve the basic design of clothing data source, and generate the information encoded of the RFID tags and track changes in product information, and other flow of information in the clothing products distribution logistics process.

2) Improve collection, analysis and implementation of the dynamic data by the use of RFID technology to build a clothing distribution logistics of all aspects of information management, for the purpose of providing empirical data to support the management of large data analysis system.

3) Given technology realization for the application of RFID technology in the core module of clothing distribution logistics management.

The overall architecture of the system

\subsection{The Overall Architecture of the System}

Overall architecture of the clothing distribution logistics management system consists of four main aspects, such as the RFID data acquisition layer, the data processing layer, the data storage layer and the application layer data. And it was shown in Figure 2. 


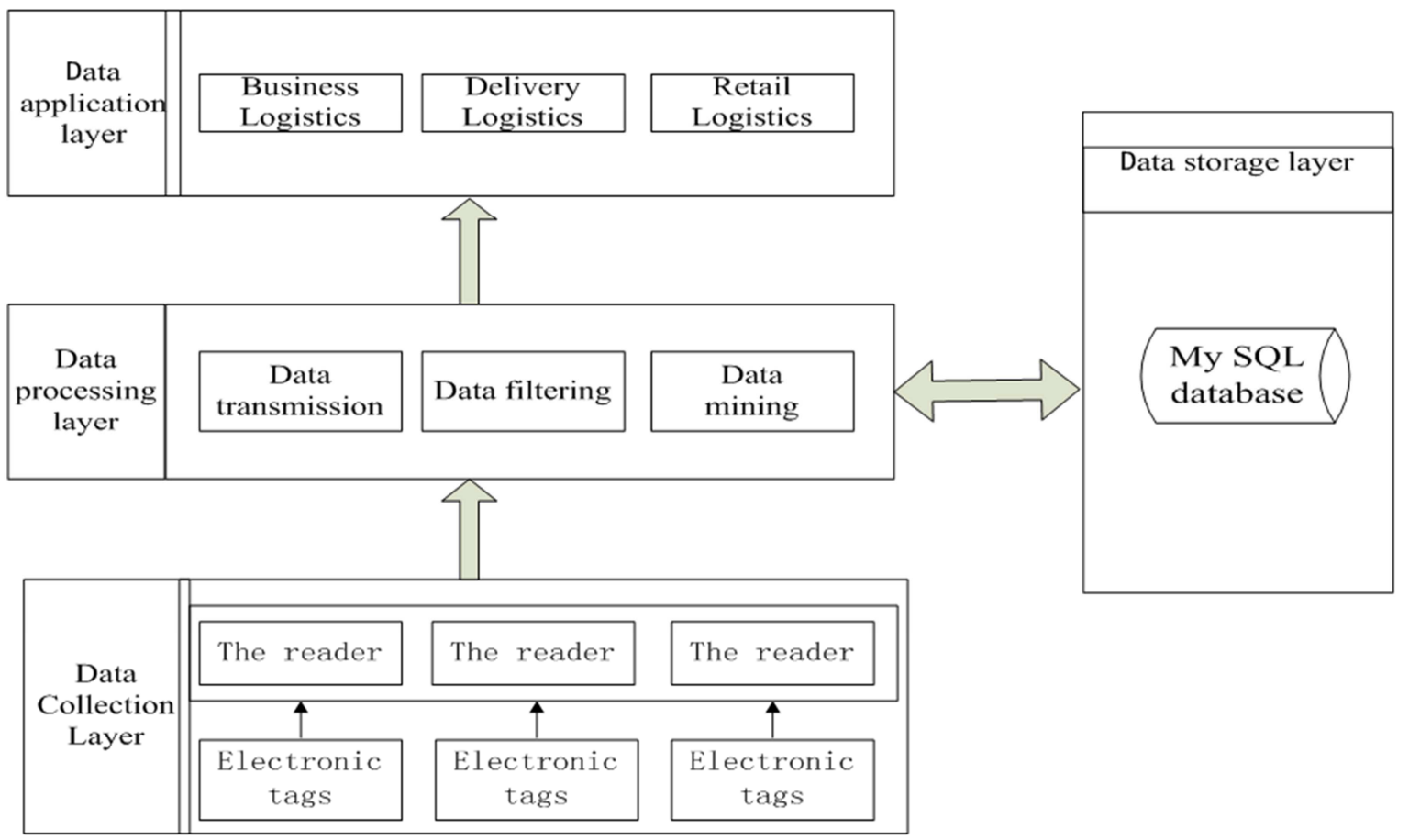

Figure 2. The overall architecture of the system.

1) Data Collection Layer:

Data acquisition layer is the ground floor of the clothing distribution logistics management system, and it consists of three components namely RFID tags, readers, and electronic tags. The electronic tag is the data source of the entire system, and all operations are based on the RFID tag by related reader for reading, then the reader transferred up to the data processing layer.

2) Data processing layer:

Data processing layer is to play the role of intermediary between the data acquisition layer and the data application layer, and its basic goal is to process the data that was collected by the data acquisition layer into the logistics information, including data transmission, filtering, mining etc. Finally they were provided to the data application layer for use.

3) Data storage layer:

The data storage layer is the center of the whole system of data storage, and the center of data server stores various data information for each business required. Therefore, it is able to provide data persistence services for the clothing distribution logistics management system.

4) Data application layer:

The main function of the application layer of the clothing distribution logistics management system is to analysis and process again for information that collected by the RFID technology after the data acquisition layer analyzing and processing again. And as a result, it can provide data and policy support to the clothing distribution logistics management system.

\subsection{The Summary}

The primary difference between RFID-based clothing distribution logistics management system and traditional clothing logistics management system is that the data collection layer is changed. And the RFID technology has a unique identification, fast scanning, read easily, and other advantages. Therefore, electronic tags and RFID reader instead of the original bar code mode that used photoelectric to scan. While the system processing layer, storage layer and application layer is on top of RFID data acquisition layer to design and improve.

\section{The Conclusion and Prospect}

The use of the RFID technology in the garment distribution logistics management system can track and control entire business process that includes clothing away from the factory, transportation, selling and eventually reach the hands of consumers. Furthermore, it can also help enterprises obtain and administrate all the real-time accurate information, so that enterprises can make rapid changes and the decision-making in the market in the shortest time, which improved resilience, adaptability and competitiveness of clothing enterprise. All in all, the combination of the RFID technology and the networking technology will have a very broad application prospects and development potential in the Chinese clothing market.

This study based on the goal of RFID application system and the enterprise logistics environment, to design the distribution logistics system architecture based on RFID data acquisition technology of clothing, and the RFID technology was used to distribution logistics process of finishing goods warehouse storage, delivery of cargo from storage to store storage, sales and warehouse inventory and so on. In addition, they can help realize the clothing automated warehousing and 
inventory management. Besides, they may improve data collection and analysis capabilities of sales information, customer information, so as to improve the quality of service to customers. But due to the limitation of time and energy as well as the knowledge level, this study only for such production enterprises how to establish distribution logistics management system based on RFID for the preliminary research and implementation. And there is much research work that needs further study in the future.

\section{Acknowledgement}

This study is sponsored by Shanghai University of Engineering Science Innovation Fund for Graduate Students. The project name is: Research and Application of Buyer Mode Operation Mechanism of the Clothing Brand Retail.

\section{References}

[1] Cao Mengru. (2013). The application and research of warehouse management system was based on the RFID [D]. Anhui Agricultural University, 2013.

[2] Sun Xiangyun, Liu Zengjin, Zheng Shuofang. (2012). Information Classification and Coding and Standardization [M] Machinery Industry Press. 2012: 198-199.

[3] Xia Hongfeng. The application of RFID in $\mathrm{J}$ garment enterprise supply chain management [D]. South China University of Technology. 2011.

[4] Fu Pujun. (2013). The study on logistics management of collaborative supply chain was based on information technology [D]. Beijing Forestry University, 2013.
[5] Ling Ruochuan. (2013). Clothing logistics management system based on RFID technology [D]. South China University of Technology, 2013.

[6] Wang Kang. (2012). Enhancing the rapid reaction capability of garment enterprise based on RFID technology [D]. Beijing Jiaotong University, 2012.

[7] Zhou Xingjian, Ye Maosheng, Zhang Ying, Guo Yumeng. (2013). Optimization and Empirical Study of textile and garment logistics process under supply chain [J]. Journal of Wuhan Textile University, 2013, 01: 15-20.

[8] Wu Jingpeng. (2015). North American garment industry distribution channels and logistics technology application analysis and Prospect of logistics technology and its application [J]. 2015, 07: 137-143.

[9] Dong Aihua, Lu Yan. (2013). Design and implementation of the management system of apparel retail shop based on wireless radio frequency technology [J]. Instrument technology, 2014, 01: 20-23+27.

[10] Xu Tao. (2012) RFID technology in the application of inventory management [D]. Southwest Jiao Tong University, 2012.

[11] Shen Qiaolu. (2013). fast fashion product inventory management [D]. Shanghai Jiaotong University, 2014.

[12] Ding Shuli. (2014). RFID technology simulation in the clothing supply chain management research [D]. North University, 2014.

[13] Hua Meng. (2013). The construction analysis of supply chain management system of L fashion company based on RFID technology [D]. Suzhou University, 2013. 